\title{
Kajian Potensi Lamun dan Pola Interaksi Pemanfaatan Sumberdaya Perikanan Lamun (Studi Kasus Kampung Kornasoren dan Yenburwo, Numfor, Papua)
}

\author{
(Potential Study of Seagrass and Interaction Pattern of Seagrass Fishery Resources Utilization \\ (Case Kampung Kornasoren and Yenburwo, Numfor, Papua)
}

\author{
Selvi Tebay ${ }^{1}$, Denny Cliff Mampioper ${ }^{1}$
}

\section{ARTIKEL INFO}

Article History

Received : 20 November 2017

Accepted : 24 Desember 2017

Kata kunci:

Lamun, Jasa ekosistem, aktivitas

masyarakat, Numfor, Papua

Korespondensi Author

1 Jurusan Perikanan, FPIK UNIPA,

Manokwari, 98314, Indonesia, email:

s.tebay@unipa.ac.id

\begin{abstract}
ABSTRAK
Ekosistem lamun memberikan jasa lingkungan bagi masyarakat yang didefinisikan sebagai semua manfaat yang berguna bagi kesejahteraan masyarakat pesisir. Penelitian ini dilakukan di pesisir Numfor Papua, kampung kornasoren dan Yenburwo selama bulan Juni-Juli 2016. Tujuan penelitian ini yaitu untuk mengkaji potensi dan jasa ekosistem lamun bagi kesejahteraan masyarakat. Sebanyak delapan jenis lamun ditemukan E. acoroides, $T$. hemprichii, C. serrulata, C. rotundata, H. ovalis, H. pinifolia, H. uninervis, dan $S$. isoetifolium. Jenis $T$. hemprichii dan E. acoroides memiliki tegakan tertinggi. $H$. pinifolia dan $H$. uninervis adalah jenis lamun tegakan terendah. Nilai persentase penutupan relatif terbesar yaitu E. acoroides sebesar 37,34\%. Indeks Nilai Penting jenis T. hemprichii 92,34 dikampung Kornasoren, sedangkan di kampung Yenburwo E. acoroides, yaitu 90,10. Bahan untuk buat jaring, pengumpulan moluska, penangkapan ikan, dan pengumpulan teripang merupakan bentuk pemanfaatan masyarakat pada ekosistem lamun. Terdapat hubungan pengaruh yang signifikan antara aktivitas pemanfaatan masyarakat terhadap persen penutupan lamun. Terdapat hubungan pengaruh yang signifikan $(p$-Value $=0,03<\alpha=0,05)$ antara aktivitas pemanfaatan masyarakat terhadap persen penutupan lamun di Kampung Kornasoren dan Yemburwo. Hasil kajian ini membuktikan bahwa perlu dilakukan pengelolaan ekosistem lamun secara komprehensif, baik aspek ekologi, sosial, dan ekonomi untuk mencapai tujuan pembangunan berkelanjutan.
\end{abstract}

\section{PENDAHULUAN}

Ekosistempadang lamun merupakan salah satu ekosistem di pesisir yang memiliki produktivitas yang tinggi. Tingginya produktivitas lamun tidak terlepas dari peranannya sebagai produktivitas primer di perairan dangkal ekosistem laut (Supriadi et al. 2012; Rangkuti et al. 2017). Selain itu, ekosistem lamun mempunyai konektivitas secara ekologi bagi biota lainnya seperti beberapa jenis ikan yang memanfaatkan lamun sebagai habitat untuk pemijahan, pengasuhan, tempat mencari makan (Latuconsia dan Rappe 2013; Assa et al. 2015; Rangkuti et al. 2017). Bahkan, organisme tertentu seperti penyu hijau (Chelonia midas) dan dugong (Dugon dugon) menjadi lamun sebagai makanannya (Rangkuti et al. 2017) termasuk organisme bentik. Ekosistem lamun juga sangat berperan dalam menstabilkan dasar perairan dengan sistem perakarannya yang 
dapat menangkap sedimen (trapping sediment), dan pelindung pantai dengan cara meredam arus (Rangkuti et al. 2017).

Secara ekonomi dan sosial ekosistem lamun juga memberikan jasa lingkungan bagi masyarakat (Tebay et al. 2012, 2013; Arkham et al. 2015; Rangkuti et al. 2017). Ekosistem lamun telah lama dimanfaatkan masyarakat sebagai daerah penangkapan ikan (fishing ground), seperti ikan baronang, kekerangan, dan lain-lain (Tebay et al. 2012; Arkham et al. 2015; Rangkuti et al. 2017). Ekosistem lamun telah lama dimanfaatkan masyarakat sebagai daerah penangkapan ikan (fishing ground), seperti ikan baronang, kekerangan, dan lain-lain (Tebay et al. 2012; Arkham et al. 2015; Assa et al. 2015). Lebih lanjut Arkham et al. (2015 ) menjelaskan bahwa ekosistem lamun merupakan salah satu perikanan skala kecil (small-scale fisheries) sangat penting yang dapat memberikan kontribusi terhadap ketahanan pangan dan peningkatan pendapatan masyarakat pesisir. Bahkan, akhir-akhir ini lamun juga telah berkembang menjadi salah satu tujuan wisata dalam bentuk wisata snorkling di laut (Tebay et al. 2013, 2014).

Berbagai kerusakan ekosistem padang lamun terjadi akibat aktivitas manusia karena keberadaan dan fungsinya sering kali diabaikan (Arkham et al. 2015; Tebay et al. 2013; Rangkuti et al. 2017). Beberapa aktivitas masyarakat secara langsung maupun tidak langsung dapat berdampak pada degradasi habitat dan keanekaragaman hayati ekosistem lamun. Arkham et al. (2015) menjelaskan perikanan skala kecil di ekosistem lamun sangat umum dilakukan karena letaknya dekat pantai, namun peran dari ekosistem lamun untuk kegiatan produksi sebagai mata pencaharian nelayan skala kecil sering diabaikan. Hal ini disebabkan kurangnya pemahaman masyarakat pesisir akan pentingnya ekosistem lamun, sama seperti eksositem pesisir lainnya (mangrove dan terumbu karang). Padahal, pemanfaatan yang dilakukan terhadap ekosistem lamun akan memberikan pengaruh terhadap struktur komunitas padang lamun dan pada akhirnya berpengaruh terhadap nilai ekonomi yang akan diperoleh.

Pulau Numfor merupakan sebuah pulau yang terletak di sebelah Utara Papua, terdapat ekosistem padang lamun dengan berbagai jenis flora dan fauna yang hidup di dalamnya (Tebaiy et al. 2012, 2014). Daerah dengan hamparan lamun yang beragam (Wanma 2014; Tebay et al. 2014) di kampung Bawei dan Yenmanu Numfor dilaporkan ada yang memiliki hamparan lamun yang luas dan ada juga yang memiliki hamparan lamun yang rendah serta berasosiasi dengan terumbu karang. Kedua desa ini telah banyak dimanfaatkan oleh masyarakat sebagai tempat mencari ikan secara tradisional ataupun berbagai jenis kegiatan yang lain (Talakua dan Paisey, 2006), namun demikian penelitian dan informasi tentang kondisi lamun dan hubungannya dengan interaksi masyarakat sangat terbatas. Melengkapi beberapa kajian, penelitian lamun tentang hubungan antar berbagai aktivitas pemanfaatan masyarakat dan kondisi ekosistem Lamun di Perairan Pesisir Numfor-Papua perlu dilakukan untuk melihat struktur habitat lamun dan pemanfaatan atau aktivitas masyarakat. Tujuan penelitian ini adalah untuk memberikan informasi tentang potensi ekosistem lamun serta berbagai aktivitas pemanfaatan masyarakat di lokasi penelitian.

\section{METODOLOGI}

\section{Lokasi Penelitian}

Penelitian ini dilakukan di Perairan Pesisir Pulau Numfor Papua, tepatnya di kampung Kornasoren dan Kampung Yenburwo. Penelitian ini dilaksanakan selama satu (1) bulan yaitu dari bulan Juni-Juli 2016. Unit analisis dalam penelitian ini yaitu Masyarakat Pesisir di Kampung Kornasoren dan Kampung Yenburwo . Kedua kampung ini mempunyai ekosistem lamun yang baik serta terdapat aktivitas masyarakat pesisir seperti nelayan yang melakukan penangkapan

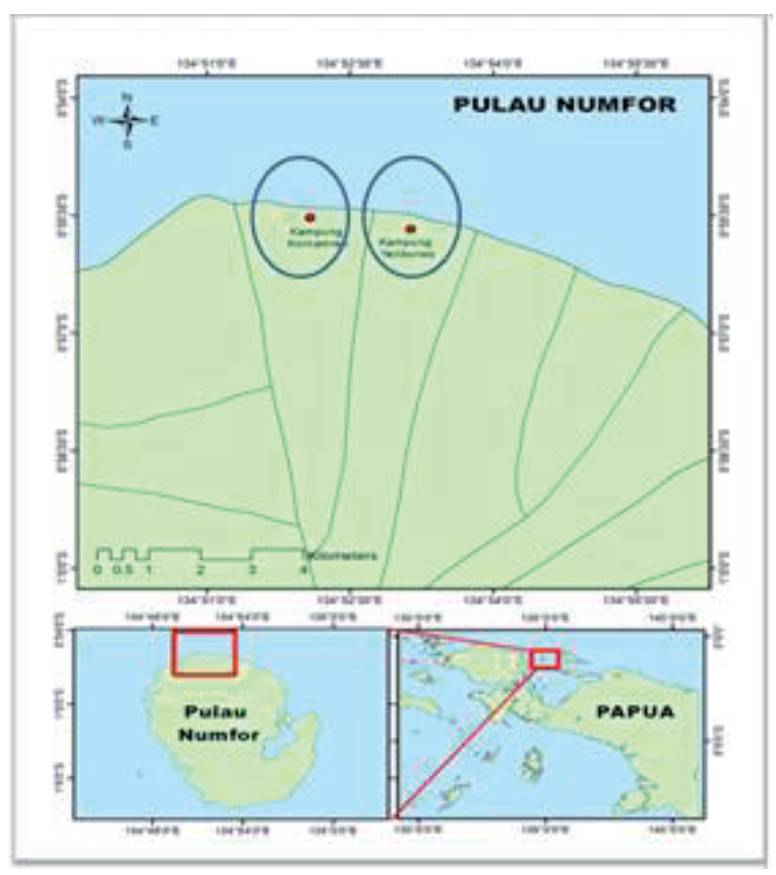

Gambar 1 Lokasi penelitian di Pulau Numfor Papua 
ikan di sekitar ekosistem lamun, mengumpulkan berbagai jenis biota, seperti moluska dan teripang yang berasosiasi dengan padang lamun. Sebagian besar kerang-kerangan (kelompok Bivalvia) dan siput (kelompok Gastropoda), serta ikan merupakan sumber makanan bagi masyarakat, dalam penelitian ini dapat dilihat pada Gambar 1.

\section{Pengumpulan Data Pengambilan Contoh Lamun}

Metode yang digunakan dalam pengambilan sampel lamun yaitu dengan menggunakan metode transek kuadrat. Pengambilan sampel dilakukan pada saat air surut terendah. Sebelum pengambilan data dilakukan terlebih dahulu pengamatan awal di lapangan terhadap kondisi penyebaran spesies lamun untuk menentukan lokasi penempatan garis transek. Jumlah kuadrat ditempatkan 10 kuadrat berukuran $50 \times 50 \mathrm{~cm}$.

Sebelum melakukan peletakan kuadrat, terlebih dahulu yang dilakukan adalah mengetahui jarak sebaran lamun dari darat ke arah laut di mana lamun terakhir dijumpai dan jarak lamun secara horizontal yaitu mengikuti batas kampung. Jarak yang telah diketahui secara vertikal ke arah laut hasilnya dibagi dengan jumlah kuadran sebanyak 10 kuadran untuk mendapatkan jarak tiap kuadran dan secara horizontal hasil pengukurannya dibagi dengan tiga subtransek untuk mendapatkan jarak antara masing-masing transek agar satu daerah titik pengambilan sampel terwakili. Hasil pengukuran jarak luasan lamun (dari darat ke arah laut dan lebar berdasarkan batas kedua kampung), jarak antartransek, dan jarak antarkuadran (Gambar 2).
Penentuan jenis lamun dilakukan secara langsung dengan mengacu pada Seagrass Watch Northern Fisheries Centre Ausralia, McKenzie et al.(2003), Azkab (1999).

\section{Bentuk Pemanfaatan Ekosistem Lamun oleh Masyarakat}

Pendekatan yang digunakan dalam penelitian ini adalah pendekatan kualitatif dan kuantitatif. Pendekatan kualitatif merupakan suatu paradigma penelitian untuk mendiskripsikan peristiwa, perilaku orang atau suatu keadaan tempat tertentu secara rinci dan mendalam yang diungkapkan dalam bentuk narasi. Penelitian ini dilakukan dengan penekanan pada penelahan deskriptif dengan metode induktif kualitatif-fenomenologi (Burhan 2007).

Metode ini dimaksudkan untuk memberikan penjelasan dan uraian berdasarkan data dan informasi dari fenomena-fenomena yang diperoleh dari hasil penelitian atau sesuatu objek yang diteliti. Data yang digunakan dalam penelitian ini adalah data primer dan sekunder, serta penentuan responden secara purposive sampling untuk menentukan aktor kunci. Aktor kunci digunakan apabila peneliti sudah memahami informasi awal tentang objek penelitian maupun informan penelitian sehingga membutuhkan responden atau masyarakat yang memanfaatkan lamun sebagai tempat penangkapan ikan dan biota lainnya untuk memulai melakukan wawancara atau observasi.

Pengumpulan data untuk penyusunan analisis peta jaringan dari berbagai aktivitas pemanfaatan oleh masyarakat pesisir diperoleh melalui wa-

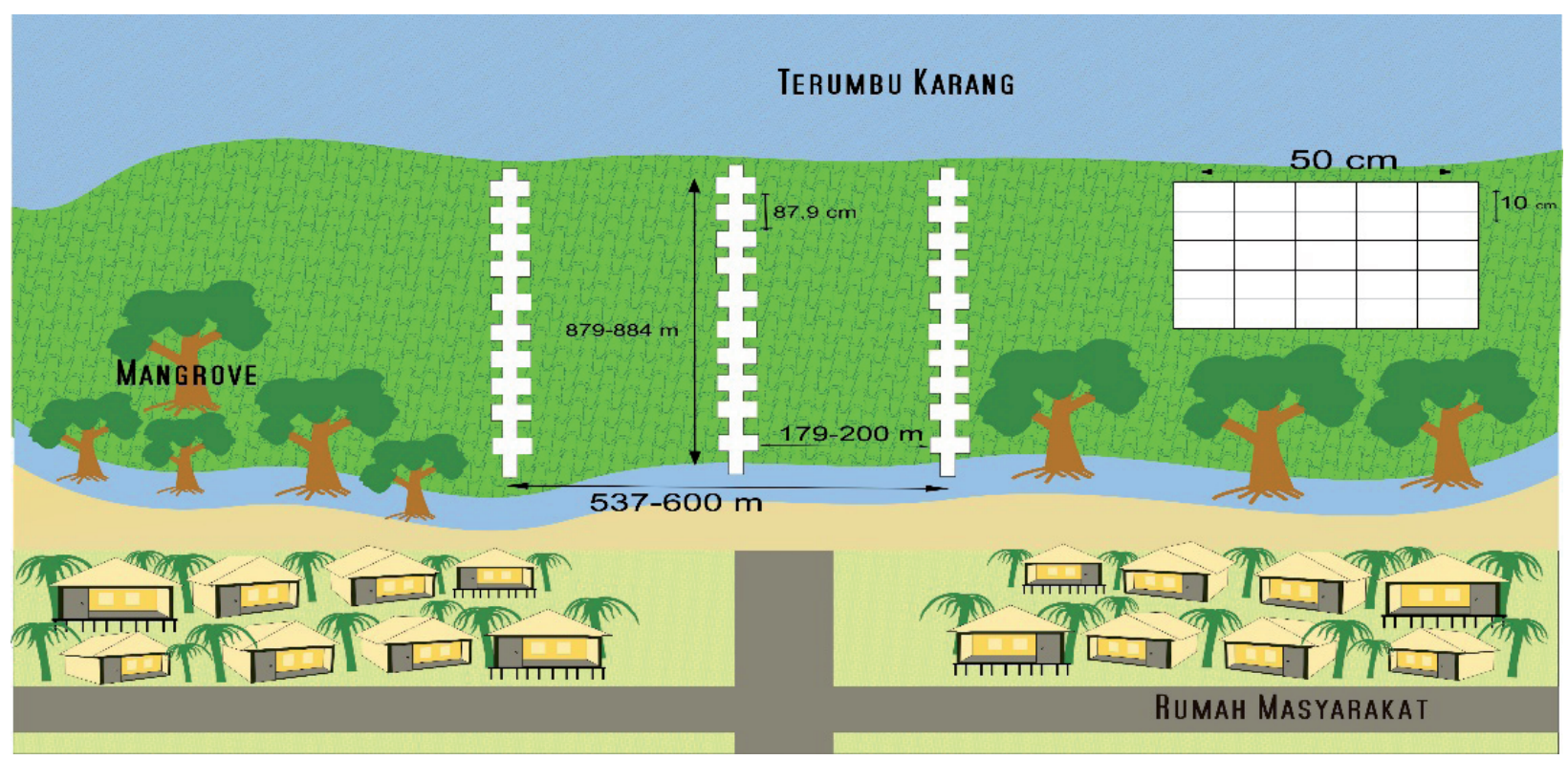

Gambar 2 Peletakan kuadrat lamun berukuran 50x50 cm 
wancara dan observasi secara langsung di lokasi penelitian. Jumlah responden dalam wawancara, yaitu 30 orang (15 orang setiap kampung). 30 orang merupakan masyarakat pesisir yang memanfaatkan lamun untuk melakukan berbagai pemanfaatan terhadap sumberdaya. Variabel yang diamati dalam penelitian ini, yaitu 1) potensi ekologi lamun mencakup: sebaran jenis, kerapatan jenis, frekuensi relatif, penutupan relatif, dan Indeks Nilai Penting (INP); dan 2) aktivitas pemanfaatan masyarakat untuk aktivitas masyarakat variabel yang diamati meliputi aktivitas harian dari kegiatan pemanfaatan seperti pengambilan teripang, pengumpulan kerang, penangkapan ikan, dan bahan dasar pembuatan jaring.

\section{Analisis Data Ekologi Lamun}

Kerapatan masing-masing jenis lamun pada setiap stasiun dihitung dengan menggunakan rumus English et al. (1994):

$$
\mathrm{Di}=\frac{\mathrm{Ni}}{\mathrm{A}}
$$

Di adalah kerapatan jenis (tegakan $/ \mathrm{m}^{2}$ ) spesies ke-i; Ni adalah jumlah individu/tegakan spesies ke-i dalam kuadrat; dan A adalah luas transek kuadrat $\left(\mathrm{m}^{2}\right)$.

Adapun penghitungan penutupan jenis lamun tertentu pada masing-masing petak dilakukan dengan menggunakan rumus:

$$
\mathrm{C}=\frac{\Sigma(\boldsymbol{M i x} \boldsymbol{f i})}{\Sigma f}
$$

$\mathrm{C}$ adalah persentase penutupan jenis lamun ke-i, Mi adalah presentase titik tengah dari kelas kehadiran jenis lamun ke-i, dan f adalah banyaknya subpetak di mana kelas kehadiran jenis lamun ke-i sama. Penutupan relatif lamun yaitu perbandingan antartutupan individu jenis ke-i dengan total jumlah tutupan seluruh jenis. Perhitungan penutupan relatif lamun dihitung dengan menggunakan rumus (English et al. (1994)) sebagai berikut:

$$
P R i=\frac{P i}{\sum P i j} \times 100
$$

PRi adalah penutupan relatif jenis lamun ke-i; Pi adalah penutupan spesis ke-i; Pij adalah total jumlah penutupan seluruh jenis.

Indeks nilai penting (INP) merupakan hasil penjumlahan dari kerapatan relatif, frekuensi relatif, dan penutupan relatif. Indeks nilai penting dapat menggambarkan suatu spesies yang memiliki peran paling penting dan pengaruh paling besar dalam suatu komunitas (English et al. 1994)

$$
\mathrm{INPi}=\mathrm{KRi}+\mathrm{FRi}+\mathrm{PRi}
$$

INPi adalah indeks nilai penting jenis ke-i; KRi adalah kerapatan relatif jenis ke-i; PRi adalah penutupan relatif jenis ke-i.

\section{Jaringan Sistem Sosial-Ekologi Lamun dan Berbagai Aktivitas Masyarakat}

Pengolahan data secara kualitatif dilakukan dengan analisis deskriptif. Analisis deskriptif merupakan metode analisis yang digunakan dengan tujuan untuk memperoleh gambaran objektif mengenai aktivitas pemanfaatan masyarakat. Gambaran objektif tersebut dapat berupa deskripsi ringkas dalam bentuk angka, peringkat, atau persentase, tabel, dan grafik (Kunto 2007). Untuk mendapatkan gambaran kondisi padang lamun secara komprehensif, data dalam bentuk tabulasi mengenai aktivitas yang dilakukan di lamun, seperti koleksi biota, penangkapan ikan, membuat tikar menggunakan lamun, membuat makanan, dan tas; ini dilakukan berdasarkan hasil pengamatan, wawancara, dan studi dokumentasi tentang kegiatan masyarakat di daerah padang lamun untuk dianalisis dan kemudian hasilnya dibuat dalam bentuk grafik dan dibahas secara deskriptif. Analisis selanjutnya untuk melihat keterkaitan antara potensi lamun dan berbagai macam aktivitas masyarakat dilakukan dengan regresi linear sederhana.

\section{HASIL DAN PEMBAHASAN}

\section{Potensi Lamun}

\section{Jenis lamun}

Berdasarkan hasil pengamatan pada kedua lokasi penelitian, telah ditemukan ada 8 jenis lamun yang termasuk dalam 2 famili (Hydrocharitaceae dan Cymodoceaceae) dan 6 genus. Kedelapan jenis lamun ini (termasuk dalam jenis pioner dan klimaks), yaitu E. acoroides, T. hemprichii, C. serrulata, C. rotundata, H. ovalis, $H$. pinifolia, $H$. uninervis, dan $S$. soetifolium. Salah satu jenis yaitu $H$. ovalis ditemukan pada suatu bidang kecil di luar kuadrat pengamatan di kedua lokasi pada substrat yang membentuk gundukan pasir sebagai tempat hidupnya. Substrat yang membentuk gundukan tersebut diduga disebabkan adanya aktivitas menggali hewan bentos untuk mencari makan atau bersembunyi (Bratakusuma 2013). 
Selvy et al. (Potential Study of Seagrass and Interaction Pattern of Seagrass Fishery Resources Utilization (Case Kampung Kornasoren and Yenburwo, Numfor, Papua))

Tabel 1 Jenis Lamun yang ditemukan di Kornasoren dan Yenburwo dan daerah lainnya di Papua

\begin{tabular}{|c|c|c|c|c|c|}
\hline \multirow{2}{*}{ No } & \multirow{2}{*}{ Taksa } & \multicolumn{4}{|c|}{ Lokasi } \\
\hline & & Kornasoren1 & Yenburwo1 & Manokwari2 & Biak Numfor3 \\
\hline \multicolumn{6}{|c|}{ Cymodoceaceae } \\
\hline 1. & Cymodocea rotundata $p$ & + & + & + & + \\
\hline 2. & Cymodocea serrulata $k$ & + & + & + & + \\
\hline 3. & Halodule pinifolia $p$ & + & + & + & + \\
\hline 4. & Halodule uninervis $p$ & + & + & + & + \\
\hline 5. & Syringodium isoetifolium $p$ & + & + & + & $\mathrm{x}$ \\
\hline \multicolumn{6}{|c|}{ Hidrocharitacea } \\
\hline 6. & Enhalus acoroides $k$ & + & + & + & + \\
\hline 7. & Halophila ovalis $p$ & $(+)$ & $(+)$ & + & + \\
\hline 8. & Thalassia hemprichii $k$ & + & + & + & + \\
\hline 9. & Halophila decipiens & $\mathrm{x}$ & $\mathrm{x}$ & $\mathrm{x}$ & $\mathrm{x}$ \\
\hline 10. & Halophila minor & $\mathrm{x}$ & $\mathrm{x}$ & $\mathrm{x}$ & + \\
\hline
\end{tabular}

$+=$ ada $; \mathrm{x}=$ tidak ada

Sumber: ${ }^{1}$ peneltian ini; ${ }^{2}$ Lefaan et al. (2013); ${ }^{3}$ Dewi et al. (2017)

Hasil penelitian lain terkait jenis lamun di daerah Papua menemukan 8 jenis lamun di Pesisir Manokwari; Leefan et al. (2013) 8 jenis di Biak (Dewi et al. 2017). Sementara di perairan lainnya seperti di Perairan Pulau Barra Lompo Makassar 3 jenis (Supriadi et al. 2012); Pantai Tongkina Sulwesi Utara 2 jenis (Assa et al. 2015); Pulau Kumbang, Kepulauan Karimunjawa terdapat 6 jenis lamun (Hartati et al. 2012); dan Teluk Banten 5 jenis (Satrya et al. 2012).

Distribusi lamun dari arah pantai hingga ke arah laut perairan kampung Kornasoren dan Yenburwo tergolong vegetasi campuran karena lamun yang ditemukan lebih dari satu jenis. Vegetasi campuran tersusun lebih dari dua atau lebih jenis lamun yang tumbuh bersama pada satu habitat dan biasanya terbentuk di daerah subtidal yang dangkal (Hartati et al. 2012). Berdasarkan pengamatan di lapangan bahwa dari arah darat vegetasi penyusun adalah jenis lamun $C$. rotundata dan C. serrulata, $H$. uninervis, $H$. pinifolia, kemudian diikuti oleh jenis T. Hemprichii dan $E$. acoroides, serta $S$. isoetifolium bercampur dengan $C$. serrulata, $C$. rotundata, dan T. hemprichii yang berhadapan langsung dengan terumbu karang.

Jenis lamun (Tabel 1) merupakan jenis-jenis lamun yang umumnya ditemukan di perairan Papua dengan jumlah atau komposisi jenis yang berbeda-beda. Hal ini dketahui dari hasil-hasil penelitian yang telah dilakukan seperti pada penelitian yang dilakukan oleh Arebo (2014) di Nabire kampung Kwatisore, di mana tercatat 10 jenis dan pada kampung Sauribru Numfor Timur tercatat 6 jenis lamun, yaitu T. ciliatum, S. isoetifolium, $H$. uninervis, $C$. rotundata,
H. ovalis, dan E. acoroides (Nakul 2015). Kartikasari et al. (2012) melaporkan di perairan Papua ditemukan 11 jenis lamun. Khusus daerah Biak Numfor ditemukan 8 jenis lamun (Tomascik et al. 1997). Jika dibandingkan komposisi jenis lamun tahun 1997 di Biak Numfor, Nabire (Kampung Kwatisore) tahun 2014 dan jenis lamun di kedua lokasi penelitian di Pulau Numfor tahun 2016, jumlah jenis yang ditemukan sedikit dan yang paling banyak jenisnya adalah di Nabire, di mana jenis yang tidak ditemukan adalah $H$. decipiens dan $H$. minor. Pada perairan kampung Sauribru yang merupakan satu distrik dengan kedua lokasi penelitian, lamun yang tidak ditemukan adalah jenis $T$. ciliatum, namun jumlah jenis di kedua kampung lebih banyak bila dibandingkan dengan jenis yang ditemukan oleh Nakul (2015).

\section{Kerapatan Jenis}

Berdasarkan hasil pengamatan diketahui bahwa perairan kampung Kornasoren dan Yenburwo ditumbuhi 8 jenis lamun yang tersebar di lokasi pengamatan. Kampung Kornasoren merupakan lokasi yang memperoleh jumlah tegakan lamun sedikit, yaitu sebanyak 2857 individu bila dibandingkan dengan kampung Yenburwo yaitu memperoleh jumlah tegakan sebanyak 3302 tegakan. Berdasarkan jenis lamun yang ditemukan, dapat dikatakan bahwa jenis lamun T. hemprichii memiliki jumlah tegakan tertinggi, yaitu sebesar 936 tegakan dan terendah adalah jenis lamun $H$. pinifolia yaitu sebesar 2 tegakan untuk kampung Kornasoren. Pada kampung Yenburwo jenis lamun E. acoroides mempunyai jumlah tegakan tertinggi yaitu sebesar 


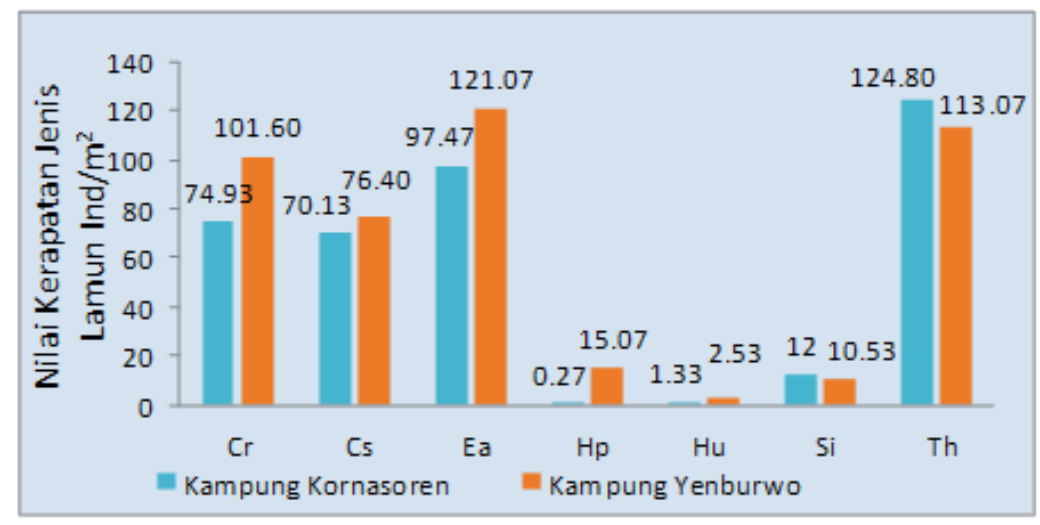

Gambar 3. Nilai kerapatan jenis lamun pada kedua lokasi penelitian

908 tegakan dan yang terendah adalah jenis lamun H. uninervis, yaitu sebesar 19 tegakan.

Secara keseluruhan bahwa jenis lamun yang memiliki jumlah tegakan tertinggi pada kedua kampung, yaitu $T$. hemprichii dengan jumlah tegakan 1784 tegakan dan diikuti E. acoroides dengan jumlah tegakan 1609 tegakan, selanjutnya diikuti oleh lamun jenis $C$. rotundata dengan jumlah tegakan yaitu 1324 tegakan, kemudian diikuti oleh jenis $C$. serrulata dengan jumlah tegakan yaitu 1099 tegakan, dan diikuti lagi oleh lamun jenis $S$. isoetifolium dengan jumlah tegakan 169 tegakan dan selanjutnya diikuti oleh lamun jenis $H$. pinifolia dengan jumlah tegakan 115 tegakan dan jenis lamun yang memiliki jumlah tegakan terendah, yaitu jenis $H$. uninervis dengan jumlah tegakan yaitu 29 tegakan.

Kerapatan jenis lamun sangat bervariasi tergantung kepada jenis lamun karena masingmasing spesies lamun memiliki tipe morfologi daun yang berbeda (Ira et al. 2012). Kerapatan spesies lamun adalah banyaknya jumlah individu atau tegakan suatu spesies lamun pada luasan tertentu. Kerapatan jenis lamun dipengaruhi oleh faktor tempat tumbuh lamun tersebut, seperti kedalaman, kecerahan, dan tipe substrat. Kerapatan jenis lamun akan semakin tinggi bila kondisi lingkungannya dalam keadaan baik (Lefaan et al. 2013; Rangkuti et al. 2017). Berdasarkan hasil perhitungan kerapatan jenis, diperoleh data yaitu jenis lamun $T$. hemprichii memiliki kerapatan yang paling tinggi dibandingkan dengan lamun jenis lain yang ditemukan pada kedua lokasi, yaitu dengan nilai kerapatan berkisar 113,07-124,80 tegakan/m²; E. acoroides 97,47-121,07 tegakan/ $\mathrm{m}^{2} ;$ C. rotundata $74,93-101,60$ tegakan $/ \mathrm{m}^{2} ; C$. serrulata 70,13-76; 40 tegakan $/ \mathrm{m}^{2} ; H$. pinifolia 0,27-15,07 tegakan $/ \mathrm{m}^{2}, S$. isoetifolium 10,53-12 tegakan $/ \mathrm{m}^{2}$. Sementara $H$. uninervis merupakan lamun dengan nilai kerapatan paling rendah dibandingkan dengan jenis lain, yaitu dengan nilai kerapatan 1,33-2,53 tegakan $/ \mathrm{m}^{2}$.

Tingginya nilai kerapatan jenis lamun terlihat dari tingginya jumlah tegakan jenis, terutama untuk jenis lamun T. hemprichii di lokasi kampung Kornasoren dan E. acoroides pada lokasi Kampung Yenburwo dan dikuti oleh jenis lamun C. rotundata, C. serrulata, dan beberapa jenis lamun lainnya yang tercatat. Jumlah tegakan dan hasil perhitungan kerapatan jenis yang didapatkan dapat dikatakan bahwa kedua jenis lamun ini menyebar pada kedua lokasi penelitian, terutama pada daerah pertengahan, di mana air saat surut mencapai $50 \mathrm{~cm}$. Jenis Lamun $T$. hemprichii dan $E$. acoroides di temukan dengan nilai kerapatan jenis yang tinggi karena kedua jenis lamun tersebut memiliki daya tahan terhadap berbagai kondisi lingkungan (Ira et al. 2012).

Hasil penelitian yang dilakukan oleh Hartati et al. (2012) bahwa jenis yang memiliki kerapatan tinggi, diduga jenis lamun tersebut mempunyai kemampuan hidup pada substrat yang cocok dan mampu beradaptasi dengan kondisi lingkungan yang ada sehingga memungkinkan spesis tersebut tumbuh. Jenis yang memiliki kerapatan rendah diduga disebabkan karena kondisi habitat yang kurang sesuai, kurangnya kemampuan berkompetisi dan kurangnya kemampuan untuk beradapasi dengan lingkungan habitat yang ada. Berdasarkan hasil perhitungan kerapatan relatif, lamun yang memiliki nilai kerapatan relatif tertinggi, yaitu jenis $T$. hemprichii dengan nilai persentase kerapatan $32,80 \%$ dari seluruh jenis lamun yang ditemukan di perairan kampung Kornasoren. Kerapatan relatif terendah, yaitu jenis $T$. pinifolia dengan persentase nilai, yaitu $0,07 \%$ dari seluruh jenis lamun yang ditemukan. Pada perairan kampung Yenburwo nilai kerpatan relatif tertinggi, yaitu jenis $T$. acoroides dengan nilai persentase kerapatan $27,50 \%$. 
Selvy et al. (Potential Study of Seagrass and Interaction Pattern of Seagrass Fishery Resources Utilization (Case Kampung Kornasoren and Yenburwo, Numfor, Papua))

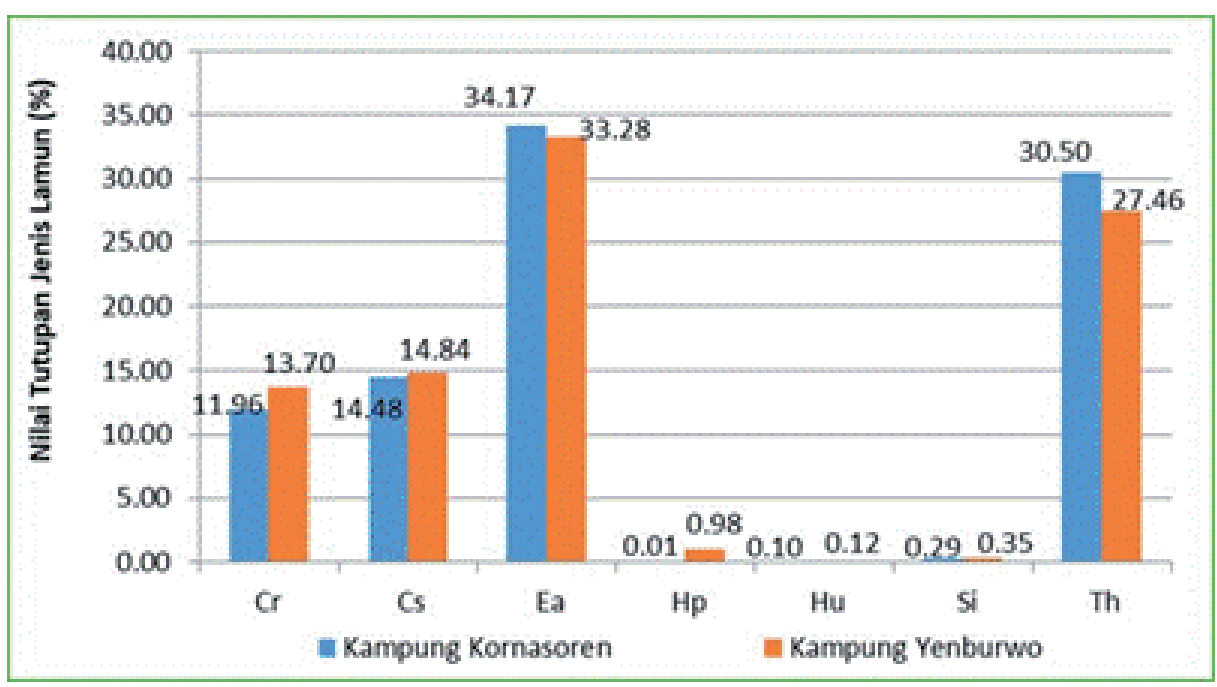

Gambar 4 Nilai tutupan jenis lamun pada kedua lokasi penelitian

\section{Penutupan Relatif}

Nilai persentase penutupan relatif tertinggi pada kedua lokasi penelitian adalah jenis lamun E. acoroides dengan nilai persentase penutupan relatif $37,34 \%$ dan $36,68 \%$. T. hemprichii $33,33 \%$ dan 30,26\%, kemudian C. serrulata dengan nilai $15,83 \%$ dan $16,36 \%$, C. rotundata $13,07 \%$ dan $15,11 \%$. Nilai persentase penutupan relatif jenis lamun yang rendah adalah S. isoetifolium $0,31 \%$ dan $0,38 \%, H$. uninervis dengan nilai persentase 0,11 dan $0,13 \%$, serta $H$. pinifolia yang memiliki nilai penutupan relatif paling rendah dari semua jenis lamum, yaitu dengan nilai persen penutupan relatif $0,01 \%$ pada kampung Kornasoren tetapi pada kampung Yenburwo jenis ini memiliki nilai persen penutupan relatif 1,08\% sedikit tinggi dari kedua jenis lamun $S$. isoetifolium dan H. uninervis.

\section{Indeks Nilai Penting Lamun}

Indeks Nilai Penting (INP) merupakan hasil penjumlahan dari kerapatan relatif, frekuensi relatif, dan penutupan relatif. Indeks nilai penting dapat menggambarkan suatu spesies yang memiliki peran paling penting dan pengaruh paling besar dalam suatu komunitas. Indeks nilai penting lamun di perairan kampung Kornasoren dan Yenburwo dapat dilihat pada Tabel 2. Semakin tinggi nilai INP suatu jenis relatif terhadap jenis lainnya, semakin tinggi peranan jenis pada komunitas tersebut. Berdasarkan hasil penelitian pada perairan kampung Kornasoren didapatkan nilai INP paling tinggi adalah untuk lamun jenis T. hemprichii, yaitu 92,34 dan perairan kampung Yenburwo INP yang paling tinggi adalah untuk jenis lamun E. acoroides yaitu 90,10.

Berdasarkan nilai INP diatas, dapat disimpulkan bahwa kedua jenis lamun tersebut memiliki nilai tertinggi pada kedua lokasi dan mempunyai peranan yang lebih tinggi dari jenis yang lain. Dengan demikian, dapat dikatakan bahwa kondisi lingkungan pada kedua lokasi mendukung bagi pertumbuhan $T$. hemprichii dan E. acoroides. INP berkaitan juga dengan kemampuan suatu jenis untuk beradaptasi dengan kondisi substrat (Lefaan et al. 2013; Rangkuti et al. 2017) dan pada lokasi penelitian pada kedua

Tabel 2 Indeks Nilai Penting (INP)

\begin{tabular}{|l|l|r|r|}
\hline Nama Jenis & Famili & Kornasoren & Yenburwo \\
\hline Cymodocea rotundata & Cymodoceaceae & 52,74 & 56,70 \\
\hline Cymodocea serrulata & Cymodoceaceae & 52,99 & 52,23 \\
\hline Enhalus acoroides & Hydrocharitaceae & 90,42 & 90,10 \\
\hline Halodule pinifolia & Cymodoceaceae & 2,58 & 9,44 \\
\hline Halodule uninervis & Cymodoceaceae & 2,96 & 3,18 \\
\hline Syringodium isoetifolium & Cymodoceaceae & 5,96 & 6,48 \\
\hline Thalassia hemprichii & Hydrocharitaceae & 92,34 & 81,87 \\
\hline Total & & $\mathbf{3 0 0}$ & $\mathbf{3 0 0}$ \\
\hline
\end{tabular}


kampung (Kornasoren dan Yenburwo) kedua jenis lamun ini mampu hidup berkembang pada subtrat pasir halus dan juga pasir sedikit agak kasar sebagai media tumbuh. Pada kedua lokasi penelitian lamun jenis E. acoroides hidup dalam kelompok kecil pada bagian darat yang hanya 1-7 individu dan terpisah-pisah dengan jarak yang tidak terlalu dekat, bahkan ada yang bercampur dengan jenis $C$. rotundata dalam jumlah sedikit. Pada bagian darat, jenis substrat yang ditumbuhi oleh jenis ini adalah subtstrat lumpur berpasir karena pada bagian darat ada tumbuhan mangrove yang juga tumbuh pada bagian darat namun tidak terlalu banyak.

Jenis lamun E. acorodes dan T. hemprichii yang merupakan jenis yang paling dominan pada daerah pertengahan hingga ke arah laut dekat dengan terumbu karang. Pada daerah sekitar inilah, masyarakat lebih banyak memanfaatkannya sebagai tempat untuk mencari ikan, entah itu dengan menggunakan kalawai (tombak) maupun dengan menggunakan jaring yang dibentangkan karena berbagai jenis ikan lebih banyak bermain dan bersembunyi di antara daun lamun pada saat air surut. Helaian daun lamun yang menutupi dasar perairan dan juga dengan kerapatan jenis masingmasing lamun menjadikan lamun sebagai tempat untuk berlindung dan berasosiasi berbagai jens ikan, teripang, dan moluska sehingga masyarakat sering memanfaatkan ekosistem lamun untuk melakukan aktvitas untuk mengambil berbagai jenis biota yang berasosasi dengan ekosistem lamun.

\section{Jaringan Sistem Sosial-Ekologi Lamun dan Berbagai Aktivitas Masyarakat}

Secara alamiah, potensi ekosistem lamun di kedua kampung (Kornasoren dan Yenburwo) dimanfaatkan langsung oleh masyarakat yang bertempat tinggal di kawasan tersebut. Masyarakat memanfaatkan langsung lamun untuk memenuhi kebutuhan hidupnya. Pola masyarakat yang terbentuk di teluk Youtefa-Jayapura menangkap ikan biasanya dilakukan oleh laki-laki, sedangkan mengumpulkan kerang atau bia, teripang dan kepiting dilakukan oleh kaum perempuan dengan berbagai alat tangkap tradisional, serta waktu yang dibutuhkan dalam penangkapan (Tebay 2012; 2013).

Empat jenis aktivitas pemanfaatan yang dilakukan masyarakat Numfor, membuat jaring, sebagai tempat mengumpulkan moluska, mengambil teripan dan menangkap ikan (Gambar 6). Pemanfaatan sumberdaya dibangun berdasarkan interaksi yang terpola sejak turun temurun. Hal yang sama dalam pengelolaan sumberdaya pesisir dan laut secara tradsional telah lama dan turun-temurun dikembangkan seperti yang dilakukan juga oleh masyarakat di kampung Tobati dan Enggros yang dikenal dengan "tradisi manjo" yakni masyarakat setempat mempunyai aturan-aturan meliputi cara pemanfaatan sumberdaya ikan serta mekanisme denda terhadap pihak yang tidak mematuh aturan yang telah ada (Tebaiy 2013).

Berdasarkan data yang diperoleh dari masyarakat di kedua Kampung tersebut, masyarakat sempat memanfaatkan jenis lamun sebagai bahan untuk membuat jaring. Volume bentuk pemanfaatan ini telah berkurang diikuti oleh ketersediaan bahan baku (nilon) di pasaran yang meningkat. Jenis lamun yang dimanfaatkan sebagai bahan pembuat jaring adalah jenis lamun E. acoroides. Bagian daun yang dimanfaatkan dari jenis lamun ini adalah bagian tepi daun yang tampak seperti benang hitam. Diambil, kemudian dijemur sampai kering dan kemudian disambung untuk dianyam menjadi jaring untuk dipakai menangkap ikan.

Bentuk pemanfaatan lain yang dilakukan oleh masyarakat di Kampung Kornasoren dan Yenburwo yaitu mencari berbagai jenis biota, seperti ikan, moluska, dan teripang, sebagian besar kerang-kerangan (kelompok Bivalvia) dan siput (kelompok Gastropoda) dan teripang di pasarkan oleh masyarakat. Bentuk pemanfaatan ini juga ditemukan pada komunitas masyarakat pesisir Teluk Youtefa Jayapura (Tebay 2012). Pada saat air surut, mereka yang umumnya kaum perempuan dan anak-anak, mencari berbagai jenis kerang-kerangan dan siput kemudian menghancurkan cangkangnya dan mengambil dagingnya untuk dikonsumsi. Namun, saat ini kegiatan untuk mencari jenis kerang-kerangan dan siput sudah jarang dilakukan dan yang lebih sering dilakukan adalah kegiatan mencari ikan dan mencari teripang.

Berdasarkan hasil wawancara dengan masyarakat setempat, dikatakan bahwa dulunya dalam melakukan aktivitas mencari teripang di sekitar daerah lamun, jenis teripang yang didapat cukup banyak. Biasanya ditampung di dalam perahu yang dipakai sampai perahu tersebut penuh Bila dibandingkan dengan sekarang, jumlah jenis teripang yang mereka dapatkan sudah tidak banyak seperti yang dulunya, yaitu hanya satu ember kecil yang dipakai untuk menampung. Khusus untuk aktivitas mencari ikan, alat yang digunakan adalah 
jaring dan kalawai dengan bantuan perahu, dan juga dengan menggunakan karung yang dibuat seperti tas untuk mengisi ikan. Jumlah ikan yang didapat biasanya hampir dua loyang yang dipakai untuk menampung. Pencarian ikan biasanya dilakukan oleh orang tua juga anak-anak muda yang selalu melaut.

Aktivitas mencari ikan biasanya pada saat air surut pada siang hari dan juga pada malam hari pada saat air pasang. Penangkapan ikan di padang lamun selain menggunakan jaring, masyarakat menggunakan kalawai. Proses penangkapannya dengan cara jaring dibentang di atas lamun membentuk setengah lingkaran untuk mengurung ikan untuk kemudian ditikam dengan kalawai. Selain itu juga, masyarakat menangkap ikan dengan membentangkan jaring pada saat malam hari di daerah terumbu karang. Interaksi yang terjadi turun-temurun ini membentuk sebuah jaringan pemanfaatan terhadap jasa lingkungan yang dihasilkan oleh ekosistem lamun.

Hasil analisis regresi menunjukkan bahwa terdapat hubungan pengaruh yang signifikan (p-Value $=0,03<\alpha=0,05)$ antara aktivitas pemanfaatan masyarakat terhadap persen tutupan lamun di Kampung Kornasoren dan Yemburwo.
Koefisien regresi sebesar 1,38 dan bertanda positif memiliki arti bahwa aktivitas pemanfaatan yang dilakukan masyarakat di kedua kampung memiliki dampak pada peningkatan tingkat kerusakan lamun yang selanjutnya akan mengurangi nilai persen tutupan lamun. Secara keseluruhan, model yang dibangun cukup baik. Hal ini terlihat dari nilai koefisien determinasi $\left(\mathrm{R}^{2}\right)$ sebesar $99,72 \%$. Nilai $\mathrm{R}^{2}$ menujukkan bahwa $99,72 \%$ variasi perubahan persen cover lamun mampu dijelaskan oleh adanya aktivitas pemanfaatan yang dilakukan masyarakat, sedangkan $0,28 \%$ dijelaskan oleh variabel di luar model yang dibangun. Kerusakan lamun di kampung kornasoren dan Yenburwor serta di perairan pulau Papua lainnya, lebih diakibatkan oleh faktor antropogenik. Seperti halnya tingginya tingkat pemanfaatan pada habitat lamun. Pemahaman tentang pemanfaatan berkelanjutan menjadi tujuan utama dalam menyikapi persoalan lingkungan khusus eko-sistem lamun yang ada. Beberapa contoh ak-tivitas antropogenik yang memengaruhi tingkat kerusakan habitat lamun antara lain adalah sampah rumah tangga, aliran limbah cair dari daratan hal ini akan memengaruhi kekeruhan perairan dan padatan terseuspensi total (TSS) (Rangkuti et al. 2017).

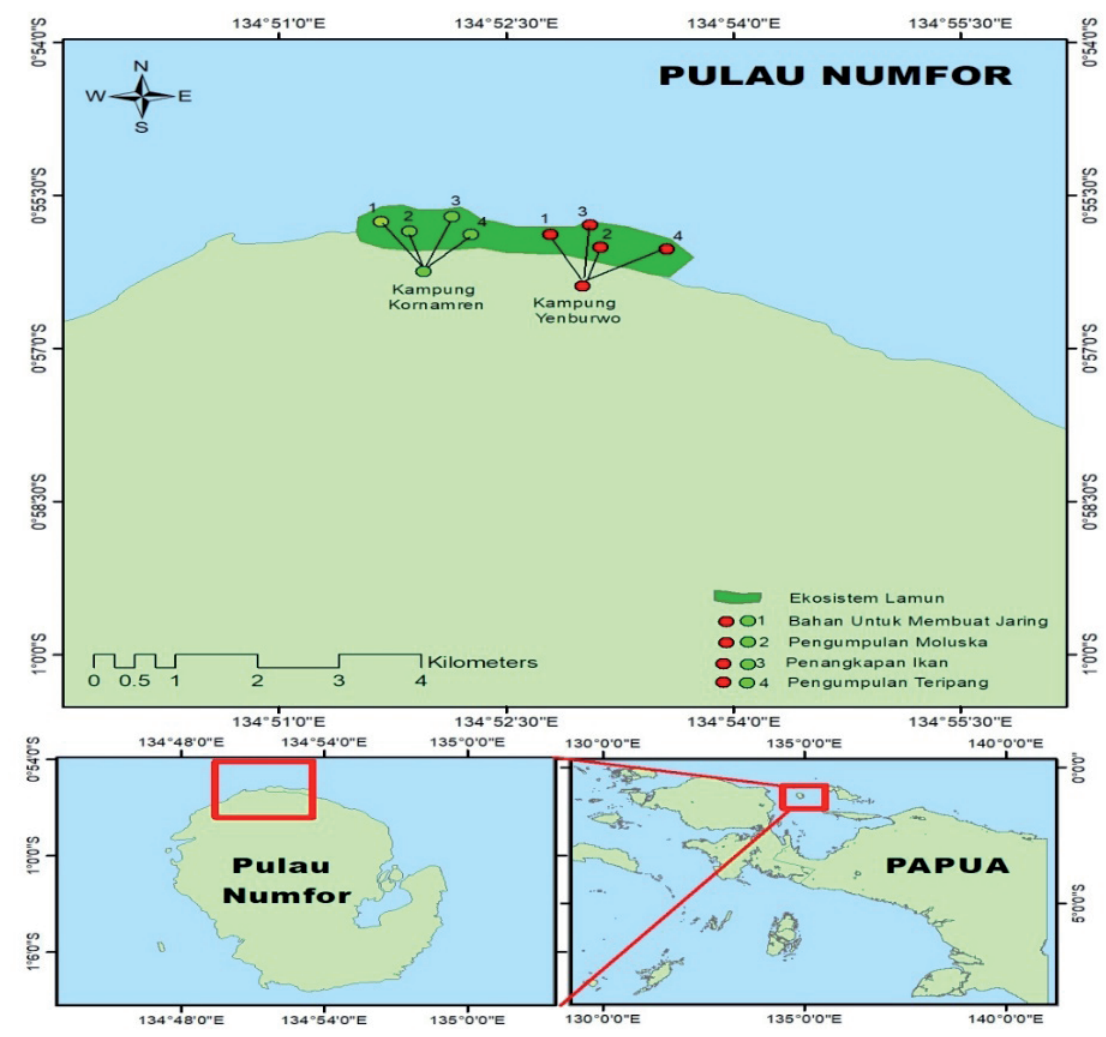

Gambar 6 Jaringan interaksi sosial ekolgi dengan berbagai aktivitas masyarakat 


\section{KESIMPULAN}

Potensi lamun di Kampung Kornasoren dan Yemburwo Numfor Papua terdapat 8 jenis lamun yang termasuk dalam 2 famili (Hydrocharitaceae dan Cymodoceaceae), yaitu Enhalus acoroides, Thalassia hemprichii, Cymodocea serrulata, Cymodocea rotundata, Halophila ovalis, Halodule pinifolia, Halodule uninervis, dan Syringodium isoetifolium. Jenis lamun T. hemprichii memiliki jumlah tegakan tertinggi yaitu sebesar 936 tegakan dan terendah adalah jenis lamun $H$. pinifolia yaitu sebesar 2 tegakan untuk kampung Kornasoren. Pada kampung Yenburwo, jenis lamun $E$. acoroides mempunyai jumlah tegakan tertinggi yaitu sebesar 908 tegakan dan yang terendah adalah jenis lamun $H$. uninervis yaitu sebesar 19 tegakan. NIP Jenis E. acoroides 90, 42 Kornasoren dan 90,10 kampung Yenburwor, untuk jenis T. hemprichii NIP 92,34 kampung kornasoren dan 81,87 kampung Yenburwo. Jasa lingkungan yang diberikan oleh ekosistem lamun dimanfaatkan oleh masyarakat dalam berbagai aktivitas pemanfaatan, yaitu bahan untuk buat jaring, pengumpulan moluska, daerah tangkapan ikan, dan pengumpulan teripang. Terdapat hubungan pengaruh yang signifikan antara aktivitas pemanfaatan masyarakat terhadap persen cover lamun. Peningkatan aktivitas pemanfaatan masyarakat sebesar $1 \%$ akan berdampak pada peningkatan tingkat kerusakan lamun sebesar $1,38 \%$.

\section{DAFTAR PUSTAKA}

Assa JD, BTh Wagey, FB Boneka. 2015. Jenis-jenis Ikan di Padang Lamun Pantai Tongkaina. Jurnal Pesisir dan Laut Tropis, 2 (1): 53-61.

Arebo BD. 2014. Komposisi dan Distribusi Jenis Lamun di Kampung Kwatisore Distrik Yaur Kabupaten Nabire, Provinsi Papua [Skripsi]. Manokwari: UNIPA.

Arkham, M Nur, L Adrianto, Y Wardiatno. 2015. Konektivitas Sistem Sosial-Ekologi Lamun dan Perikanan Skala Kecil di Desa Malang Rapat dan Desa Berakit, Kabupaten Bintan, Kepulauan Riau. Jurnal Ilmu dan Teknologi Kelautan Tropis 7(2): 433-451.

Azkab MH. 1999. Pedoman Inventarisasi Lamun. Balai Penelitian Biologi Laut, Puslitbang Oseanologi LIPI. Jakarta.

Bungin, Burhan. 2007. Penelitian Kualitatif. Jakarta: Prenada Media Group
Bratakusuma, NFM Sahami, S Nursina. 2013. Komposisi Jenis, Kerapatan Dan Tingkat Kemerataan Lamun Di Desa Otiola Kecamatan Ponelo Kepulauan Kabupaten Gorontalo Utara. Jurnal Ilmiah Perikanan dan Kelautan 1(3): 1-8.

Dewi Citra SU, B Subhan, D Arafat. 2017. Keragaman, kerapatan dan penutupan lamun di perairan Pulau Biak, Papua. Depik 6(2): 122-127. DOI: 10.13170/depik.6.2.6227

English S, Wilkinson C, Baker VJ. 1994. Survey Manual for Tropical Marine Resources. ASEAN-Australia Marine Project. Australia.

Hartati R, A Djunaedi, Hariyadi, Mujiyanto. 2012. Struktur Komunitas Padang Lamun di Perairan Pulau Kumbang, Kepulauan Karimunjawa. Ilmu Kelautan 17(4): $217-$ 225.

Ira, Dedi O, Juliatyi. 2012. Kerapatan dan Penutupan Lamun pada Daerah Tanggul Ombak di Perairan Desa Terebino Provinsi Sulawesi Tengah. Aquasains 1(2): 89-96.

Kunto YS. 2007. Ananlisis Pasar Pelanggan Pria Produk Facial Wash di Kota Surabaya. Jurnal Manajemen Pemasaran 2(1): 21-30.

Latuconsina Husain, Rohani Ambo-Rappe. 2013. Variabilitas harian komunitas ikan padang lamun perairan Tanjung Tiram-Teluk Ambon. Jurnal Iktiologi Indonesia 13(1): 35-53.

Lefaan PT, D Setiadi, D Djokosetiyanto. 2013. Struktur Komunitas Lamun di Perairan Pesisir Manokwari. Maspari journal 5(2): 69-81.

McKenzie LJ, SJ Campbell, CA Roder. 2003. Seagrass-Watch: Manual for Mapping \& Monitoring Seagrass Resources by Community (Cityzen) Volunteers, 2nd Edition. The State of Queensland, Department of Primary Industries. Australia. $104 \mathrm{pp}$

Nakul Suzannah 2015. Sebaran Lamun di Desa Sauribru Distrik Poiru Kabupaten Biak Numfor. Manokwari: Universitas Papua.

Rangkuti A, MMR Cordova, A Rahmawati, Yulma, E.H. Adimu. 2017. Ekosistem Pesisir dan Laut Indonesia. Jakarta: PT Bumi Aksara. 482 hal.

Satrya C, M Yusuf, M Shidqi, B Subhan, D Arafat. F Anggraeni. 2012. Keragaman Lamun di Teluk Banten, Provinsi Banten. Jurnal Teknologi Perikanan dan Kelautan 3(2): 29-34. 
Supriadi, RF Kaswadji, DG Bengen, M Hutomo. 2012. Produktivitas Komunitas Lamun di Pulau Barrang Lompo, Makassar. Jurnal Akuatika 3(2): 159-168.

Talakua S, Anjeli S Paisey. 2006. Struktur Komunitas Ikan Padang Lamun pada Perairan Pantai Rendani Manokwari. Jurnal Ilmiah Perikanan dan Kelautan 2(2): 119 127.

Tebay S. 2012. Kontribusi Ekonomi Sumberdaya Padang Lamun Berdasarkan Fungsinya Sebagai Habitat Ikan Di Teluk Youtefa Jayapura Papua. Prosiding Seminar Nasional Ikan ke-8, Jurusan Perikanan Fakultas Peternakan Perikanan dan Ilmu Kelautan UNIPA. Papua Barat. Hal: 143-152.
Tebay S. 2013. Pola Pemanfaatan Sumberdaya Perikanan oleh Masyarakat Teluk Youtefa Jayapura. Prosiding Seminar Nasional Riset dan Kebijakan Sosial Ekonomi Kelautan dan Perikanan Tahun 2013, Jurusan Perikanan Fakultas Peternakan Perikanan dan Ilmu Kelautan UNIPA. Papua Barat. Hal: 143152.

Tebay S, Ferdinand Y, Achmad F, Ismudi M. 2014. Struktur Komunitas Padang Lamun dan Strategi Pengelolaan di Teluk Youtefa Jayapura Papua. Jurnal Segara, 10(2): 137146.

Wanma BPD. 2014. Konektivitas Ekosistem Pesisir Sebagai Habitat Mencari Makan bagi Ikan Karang di pulau Numfor [Skripsi]. Manokwari: UNIPA, 